\title{
A APRENDIZAGEM E O TRANSTORNO DO DÉFICIT DE ATENÇÃO E HIPERATIVIDADE: Uma Análise da Produção Brasileira
}

\author{
Francisca Graziele Costa Calixto ${ }^{1}$ \\ Stela Lopes Soares ${ }^{2}$ \\ Francisco Ullissis Paixão e Vasconcelos ${ }^{3}$
}

\begin{abstract}
RESUMO
O presente trabalho tem como intuito investigar o tema Transtorno do Déficit de Atenção e Hiperatividade - TDAH - no âmbito da educação brasileira, mais especificamente as perspectivas do meio científico a respeito do diagnóstico nas salas de aula regulares e suas consequências, mediante uma pesquisa bibliográfica. Neste sentido, foram analisados 24 artigos da base de dados Scielo Brasil, em um recorte dos últimos 10 anos (2007-2017). Tivemos como resultado que os artigos correspondem à área médica, mais especificamente à clínica médica, neurociências, fonoaudiologia e psicologia. A maioria deles aborda o TDAH pela perspectiva neurobiológica com terapêutica medicamentosa. Os outros apontam para a problemática da emergência do grande número de escolares diagnosticados e medicalizados. Conclui-se que é uma discussão nova que busca o olhar multidisciplinar e a dimensão crítica da aprendizagem de pessoas diagnosticadas com esse transtorno.
\end{abstract}

Palavras-chave: TDAH. Aprendizagem. Diagnóstico. Medicalização.

\section{LEARNING AND ATTENTION DEFICIT HYPERACTIVITY DISORDER: AN ANALYSIS OF BRAZILIAN PRODUCTION}

\section{ABSTRACT}

The present work aims to investigate the topic Attention Deficit Hyperactivity Disorder-ADHD in the Brazilian education context. More specifically the perspectives of the scientific environment regarding the diagnosis in the regular classrooms and its consequences through a bibliographic research. In This sense, 24 articles from the Scielo Brazil database were analyzed in a cut-off in the last 10 years (2007-2017). We have as a result that the articles correspond to the medical area, more specifically the medical clinic, neurosciences, speech therapy and Psychology. Most of them approach ADHD from a neurobiological perspective with drug therapy. The others point to the problem of the emergence of the large number of schoolchildren diagnosed and medicalized. It is Concluded that it is a new discussion that seeks the multidisciplinary look and the critical dimension of the learning of people diagnosed with this disorder.

Keywords: ADHD. Learning. Diagnosis. Medicalization.

RECEBIDO EM: $14 / 4 / 2019$

ACEITO EM: 27/5/2019

\footnotetext{
1 Autora correspondente. Secretaria de Educação de Sobral - Seduc Sobral. Rua Caetano Figueiredo, Cohab II. 62050-845. Sobral/CE, Brasil. http://lattes.cnpq.br/1901591531064427. http://orcid.org/0000-0001-6221-1063. graziele_costa@hotmail.com

2 Centro Universitário Inta/Uninta. Sobral/CE, Brasil. http://lattes.cnpq.br/6884284520373325. http://orcid.org/0000-0002-5792-4429

3 Universidade Estadual Vale do Acaraú - UVA. Sobral/CE, Brasil. http://lattes.cnpq.br/6254266310344352. http://orcid.org/0000-00034742-1681
} 
A construção deste trabalho parte da necessidade de um alinhamento conceitual referente a um percurso de ensino junto a um aluno diagnosticado com Transtorno do Déficit de Atenção e Hiperatividade (TDAH). Ao longo deste percurso, no desempenho da função de docentes particulares, pôde-se observar tensionamentos no eixo família-aluno-escola que incidiram sobre todo o processo de aprendizagem do jovem com TDAH. Essa experiência de docência particular estendeu-se durante toda a formação inicial de um dos participantes deste estudo. Nesta, a mesma teve a oportunidade de acompanhar um jovem dos seus 11 aos 15 anos, posto que o mesmo recebeu diagnóstico de TDAH aos 4 anos de idade segundo relatos da genitora. Nessa trajetória, visualizaram-se, sob um ângulo diferenciado, os desafios e conquistas de uma criança que leva consigo esse diagnóstico como uma sentença da qual não parece se desvencilhar, bem como o posicionamento da família que buscava na escola um lugar de parceria, mas, de certa forma, encontrou muros e espinhos. Isto impulsionou-nos a investigar os discursos que estão por trás de tudo que temos visto sobre este Transtorno, para entendermos como se constitui essa teia de relações com o intuito de ampliar o olhar crítico não somente da categoria psicólogo, mas de todos os profissionais da educação.

Tendo em mente essa seara em que se constitui a aprendizagem, pretende-se, com a análise do tema, vislumbrar as perspectivas a respeito desse diagnóstico tão recorrente nas escolas brasileiras atualmente, considerando que a implicação social do tema reverbera em diferentes níveis, tanto na escola quanto na família. Ao conhecer um sujeito com um transtorno, respondemos a determinada demanda que necessita ser investigada e problematizada.

Como iremos caracterizar, posteriormente, o diagnóstico recorrente de sujeitos na fase escolar aponta para fatores que não raramente são levados em consideração e que poderiam ser primordiais para o processo de aprendizagem e diminuição dos índices de fracasso escolar. O fator neurobiológico tem sido decisivo para a construção desse diagnóstico, pois trata de aspectos do sujeito que desresponsabiliza o contexto social deste. Essa supervalorização é apoiada pela afirmação de que o TDAH é de base genética e que a resposta positiva ao medicamento ajuda a dar essa sentença ao aluno. Observamos na literatura que a conduta medicamentosa nasce antes mesmo do quadro de sintomas apresentado como transtorno. Outro fator relevante é a prevalência desses diagnósticos a partir do desempenho escolar.

A inquietude, a falta de atenção e a impulsividade, são comportamentos que prejudicam de maneira determinante o desempenho escolar. Vemos corriqueiramente jovens diagnosticados com TDAH apresentando, como comorbidades, transtornos específicos de aprendizagem, como dislexia, discalculia, etc. A elaboração de questionamentos a respeito das metodologias utilizadas em sala de aula permite, muitas vezes, caracterizar problemas de ensino-aprendizagem.

Desta forma, busca-se conhecer de que maneira os estudos em educação no Brasil têm abordado a aprendizagem no que diz respeito ao aluno com TDAH, problematizando de que modo o sistema educacional vigente tem contribuído para, de fato, comprometer-se com o direito constitucional de educação para todos ou para proliferar o fechamento desmedido desse diagnóstico nas escolas. Elencando essas problemáticas, podemos ampliar nossa visão crítica enquanto psicopedagogos quando lidamos com os 
problemas de aprendizagem que, muitas vezes, estão atrelados como uma comorbidade a determinados diagnósticos psiquiátricos. É necessário termos clara nossa missão também enquanto educadores, que constroem juntos o sistema educacional brasileiro, buscando que sejam cumpridos os direitos constitucionais.

As escolas brasileiras têm corroborado o discurso hegemônico e higienista de encontrar justificativas para o modelo falido que antecede o fracasso escolar. Vemos cada vez mais profissionais da educação agirem sob a lógica do encaminhamento como se o que houvesse de errado com o aluno fosse algo de sua inteira responsabilidade biológica e, por vezes, social. O desconhecimento e a falta de visão crítica da realidade fortalecem essas práticas.

Para isso, o presente trabalho foi construído pela análise de diferentes olhares encontrados a partir de estudos dentro de uma base de dados. Trata-se de uma pesquisa qualitativa de caráter bibliográfico, como descreve Gil (2002, p. 44):

“[...] a pesquisa bibliográfica é desenvolvida com base em material já elaborado, constituído principalmente de livros e artigos científicos". A principal vantagem da pesquisa bibliográfica está no fato de permitir ao investigador a cobertura de uma gama de fenômenos muito mais ampla do que aquela que poderia pesquisar diretamente (idem, p. 45). Sua finalidade é colocar o pesquisador em contato com o que já se produziu e se registrou a respeito do tema de pesquisa. Tais vantagens revelam o compromisso da qualidade da pesquisa.

Foi realizada uma interpretação das informações encontradas nos últimos dez anos trazendo uma perspectiva problematizadora para o tema supracitado. A pesquisa foi realizada na base de dados Scielo Brasil do ano de 2007 a 2017, tendo como descritores: TDAH e aprendizagem. A coleta de dados aconteceu entre outubro de 2018 e fevereiro de 2019.

Foram analisados, portanto, 24 artigos $^{4}$ que tratam o TDAH sob diversos olhares, que coadunam tanto para a perspectiva neurobiológica vigente sobre o tema quanto para problematizar a grande proliferação do diagnóstico na educação brasileira. A pesquisa também foi ampliada para as diversas áreas temáticas, como: psicologia educacional; reabilitação; educação e pesquisa educacional; linguística; audiologia e fonodiaulogia; medicina; neurociência; psiquiatria; psicologia; psicologia clínica; saúde pública, ambiental e ocupacional; questões sociais.

\section{OS HOLOFOTES PARA O TDAH}

O Transtorno do Déficit de Atenção e Hiperatividade (TDAH) constitui um quadro clínico e crônico (ARGOLLO, 2003). Ele é caracterizado pelos manuais Classificação Estatística Internacional de Doenças e Problemas Relacionados à Saúde (CID-10) e Manual de Diagnóstico e Estatístico de Transtornos Mentais (DSM-V) como um conjunto de sintomas que acomete indivíduos na fase inicial do desenvolvimento e que se prolonga até

\footnotetext{
4 Um dos artigos foi removido da análise, pois, apesar de usar TDAH como descritor, o conceito foi usado apenas como critério de exclusão em um recorte de estudo sobre Dislexia (CAPELLINI, S. A. et al. Desempenho em consciência fonológica, memória operacional, leitura e escrita na dislexia familial. Pró-Fono-Revista de Atualização Científica, 19(4), p. 374-80, out./dez. 2007.
} 
a idade adulta. $O$ conjunto de sintomas que caracteriza esse transtorno é uma das principais razões do fracasso escolar no cenário brasileiro, portanto vem se tornando um problema de saúde pública. Como forma de tratamento, a maneira mais eficiente tem sido a utilização de drogas estimulantes de neurotransmissores que, supostamente, não estão presentes em determinadas sinapses nos indivíduos com TDAH. Muito se tem pesquisado a respeito, mas ainda estamos à mercê de lacunas que dificultam a interação social bem como o desempenho escolar e o desenvolvimento desses indivíduos.

Historicamente, o Transtorno do Déficit de Atenção e Hiperatividade (TDAH) foi especificado, no Brasil, como "lesão cerebral mínima", por volta da década de 40, e, posteriormente, em 1962, foi modificado para "disfunção cerebral mínima" (COUTO; MELO-JUNIOR; GOMES, 2010), para denominar sintomas que foram e são tomados como causadores do fracasso escolar. Nas décadas de 80 e 90, no mundo, como um movimento da psiquiatria, o TDAH ganhou publicidade, tendo ainda, como solução medicamentosa, o Metilfenidato, substância estimulante do sistema nervoso central que está no mercado com os nomes comerciais Ritalina e Concerta. Em 1994 entra como transtorno reconhecido no DSM-IV (CALIMAN, 2008). Essa breve retomada histórica nos ajuda a interpretar o que reverbera atualmente em nossa cultura no que diz respeito à produção do TDAH como discurso presente nas escolas e nas famílias como marcante na definição de infância atualmente, bem como o cenário da indústria farmacológica vigente.

Por ser o desenvolvimento um dos fatores de observação do quadro de TDAH, é por meio da análise deste que podemos reconhecer a presença deste transtorno. $O$ quadro clínico envolve, dentre outras, dificuldade de se concentrar em atividades que exijam atenção, permanecer quieto por médio e longo período de tempo, dificuldade de organizar as atividades, perder com facilidade os materiais utilizados para determinada atividade, etc. (ARGOLLO, 2003). São comportamentos que vão tornar a vida escolar mais dificultosa, podendo culminar no fracasso escolar. Argollo (2003) destaca como importante na direção do tratamento a psicoterapia, os fármacos e a orientação dos pais para que a rotina seja bem delineada sem muitas mudanças. Na sala de aula devem ser desenvolvidas atividades curtas, intercaladas com atividades físicas e espacialmente manter a criança na primeira fileira, longe de porta e janelas (ARGOLLO, 2003).

Principalmente em relação ao diagnóstico que ocorre por volta dos sete anos de idade, "O distúrbio TDAH é caracterizado por comportamentos crônicos, com duração de no mínimo seis meses, que se instalam definitivamente antes dos sete anos" (CAPOVILLA apud COUTO; MELO-JUNIOR; GOMES, 2010). Com isso, a escola tem sido um dos principais agentes de observação dos sintomas e constatação do transtorno. O diagnóstico depende do relato dos pais e dos profissionais que lidam com a criança no ambiente escolar, mas é especialmente clínico. A questão é que um único olhar para os sintomas pode não diagnosticar de maneira clara, necessitando informações para além do consultório. Nos últimos anos tem-se atentado para a necessidade de um diagnóstico multiprofissional, mas que ainda exclui a investigação das possibilidades de aprendizagem independentemente dos comportamentos que não se enquadram. 
O diagnóstico do TDAH é clínico e se baseia, fundamentalmente, nos sintomas atuais, no caso de crianças, ou na combinação entre sintomas atuais e história clínica pregressa do comportamento no caso de adultos. O tratamento do TDAH é multimodal, envolvendo intervenções psicossociais e psicofarmacológicas (GOMES et al., 2007, p. 95). A escola tem sido o local mais corriqueiro de apontamento dos sintomas. Isso deve-se ao fato de que a escola demandar diversas atribuições ao indivíduo e, com a incapacidade de alguns de desenvolver determinadas atribuições, abrem-se possibilidades de se investigar um possível transtorno. A constatação neurológica e a melhora significativa com a utilização do medicamento, são dilemas que colocam em voga questionamentos a respeito das práticas educacionais e do desenvolvimento infantil. Especificamente, as insuficiências nos circuitos do córtex pré-frontal e amígdala, a partir da neurotransmissão das catecolaminas, resultam nos sintomas de esquecimento, distração, impulsividade e desorganização (ARMSTEN; LI, 2005 apud COUTO; MELO-JUNIOR; GOMES, 2010). De que maneira uma criança diagnosticada com esse transtorno pode lidar com esse dilema? O medicamento de fato é essencial? Que consequências isso teria para o desenvolvimento uma vez que o sujeito se torna dependente da droga? "A utilização de medicamentos visa estimular o sistema nervoso central (SNC), aumentando a disponibilização dos neurotransmissores, dopamina e norepinefrina em partes específicas do cérebro" (COUTO; MELO-JUNIOR; GOMES, 2010). Não podemos deixar de atentar para a existência de efeitos colaterais que comprometem o funcionamento saudável do organismo. "A principal desvantagem do metilfenidato é ter curto efeito de ação, sendo necessário de três a quatros doses no dia. Os principais efeitos colaterais são a diminuição do apetite, insônia, irritabilidade, cefaleia e tontura" (ELIA; AMBROSINI; RAPOPORT, 1999 apud ARGOLLO, 2003). São as crianças as mais afetadas pelas consequências advindas de diversas formas de se olhar o TDAH. É uma doença que necessita de um cuidado multiprofissional, sendo muitas vezes essa visão, de certa forma, conflitante, pois a questão medicamentosa interfere significativamente no comportamento da criança, porque existe a possibilidade de esta desenvolver um quadro de dependência comprometendo os setores da vida do indivíduo na falta dessa medicação. De fato, todas essas questões podem ser pontos de partida para discussões sobre o que se caracteriza como TDAH. Acreditamos que esses são desafios importantes para a educação, tanto no quesito do desenvolvimento de estratégias de aprendizagem quanto de consolidação da visão a respeito deste transtorno.

Em contrapartida, alguns autores compreendem a psicopatologia infantil como uma maneira de atender à demanda de uma ordem social. A psicopatologia infantil não surgiu de uma descoberta de uma patologia pertencente apenas a crianças, mas, sim, foi fruto do desejo da Psiquiatria de atender, cada vez mais, a diversos tipos de demandas e fazer com que seu saber estivesse presente e operando sobre as exigências de controle social por parte da sociedade. Vorcaro (2011) afirma que a psiquiatria infantil surge 
...da necessidade de encontrar um pedestal, um alvo onde se possam enraizar, sob a forma de uma pré-síntese, todas as anomalias e patologias do adulto, de designar um possível objeto de intervenção para uma prática que não pretende mais limitar-se a gerir os reclusos, mas, sim, presidir a inclusão social (VORCARO apud DONZELOT, 1986, p. 219).

Desta forma, esta surge como uma tentativa de diagnosticar, classificar e enquadrar, em um conceito, aquilo que foge do ideal muitas vezes sonhado pelos pais: o ideal da criança perfeita. A criança que acaba por fugir deste ideal gera um mal-estar que, na concepção não só dos pais como, também, da sociedade, precisa ser eliminado a qualquer custo. Para isso, o Manual Diagnóstico e Estatístico de Transtornos Mentais (AMERICAN..., 2014) apresenta suas categorias diagnósticas que, para tentar atender à satisfação das pessoas cada dia mais, apresenta novas categorias e sintomas. Assim, cada um de nós pode se enquadrar não só em um, mas em diversos termos catalogados por este manual.

A partir disso, ocorre o surgimento de técnicas terapêuticas e novas formas de tratamento e drogas, com a pretenciosa intenção de satisfazer pais, família e sociedade fazendo, ou melhor, tentando fazer com que a criança se enquadre no que é socialmente aceito e idealizado.

\section{AS PERSPECTIVAS CIENTÍFICAS ATUAIS NO BRASIL}

A análise foi pautada em averiguar o conteúdo trazido nos textos a respeito da visão dos autores sobre o referido transtorno e o lugar dado por estes aos sujeitos estudados. Vimos que os artigos correspondem à área médica, mais especificamente à clínica médica, neurociências, fonoaudiologia e psicologia. Todos preocupados em compreender a aprendizagem sob perspectivas diferentes.

Deste modo, observou-se que 12 artigos consideram o TDAH como um transtorno de base neurológica que pode comprometer a linguagem, a leitura, a escrita e até mesmo a aprendizagem da matemática. Ou seja, geralmente está associado a transtornos específicos da aprendizagem, como disgrafia, dislexia e discalculia. Esse transtorno, de acordo com as informações coletadas, é percebido no ambiente escolar por conta da presença de episódios de desatenção e hiperatividade que acabam reverberando no desempenho escolar que se constitui pela aquisição da leitura e da escrita. Esses estudos utilizaram-se de testes que medem essa capacidade de aquisição, sempre levando em consideração, como base, o diagnóstico de TDAH.

Diante disso, dos 12, 3 artigos procuraram pesquisar a respeito de processos de subjetivação, porém tomaram como base determinante do contexto social o diagnóstico. Ao levar em consideração o olhar dos pais, alunos e professores, partiam do pressuposto de que as consequências vinham do não enquadramento social dos sujeitos diagnosticados, até mesmo no sentido de culpabilização da família pelo comportamento não aceitável dos filhos. Também apontam para um desconhecimento por parte dos professores a respeito da categorização do quadro de sintomas, deixando estes à mercê do diagnóstico médico. Apesar de apontarem que o diagnóstico é multiprofissional, é o médico que deve dar o veredito final. Queixam-se, assim, do diagnóstico tardio, que 
implica dificuldade de continuidade do tratamento; tratamento este que é pautado no consumo do Mentilfenidato como primeira alternativa e, em segundo plano, psicoterapia e atendimento psicopedagógico.

Mesmo que o TDAH esteja entre os distúrbios psicológicos infantis mais bem estudados, ainda há muito que não se sabe. O TDAH permanece mal compreendido e controverso nas mentes do público em geral e das autoridades educacionais. É importante investigar as possíveis causas do TDAH, mas é importante também investigar as medidas educacionais preventivas e protetoras de comorbidades. Mais importante ainda é capacitar o quadro docente para melhor compreender e diferenciar as características dos alunos, evitando enquadrá-los em falsos rótulos (JOU et al., 2010, p. 34).

É importante atentar que, mesmo sob a circunstância do diagnóstico, os estudos deixam claros que não existe comprovação neurobiológica para a existência do TDAH como uma lesão no cérebro. Este uma herança recente do termo "DCM", cunhado em 1962, no mesmo período da criação das drogas que moldavam comportamentos antes da criação da categoria TDAH.

A Disfunção Cerebral Mínima (DCM) surge, então, da impossibilidade de se comprovar a anormalidade biológica, tendo-se como saída a possibilidade de presumir uma disfunção que seria uma alteração funcional sem correspondência anatômica (BENEDETTI; ANACHE, 2014, p. 443).

Considerado ainda, pelos manuais, como uma disfunção, utiliza-se do tratamento medicamentoso associado à doutrinação de comportamentos socialmente aceitáveis.

A partir de 2012 começa-se a problematização de fato em torno da natureza do diagnóstico e da grande utilização do Metilfenidato como alternativa mais eficaz, mas que apaga o sujeito em suas formas de subjetivação e não resolve os problemas de aprendizagem. De fato, o uso da medicação minimiza a incidência dos comportamentos inadequados, porém não garante uma aprendizagem efetiva por parte dos alunos.

Onze artigos, a maior parte deles publicados de 2013 a 2017, trazem, de fato, a problemática do diagnóstico atrelado à medicação, bem como práticas pedagógicas ineficazes que culminam em um processo de medicalização exacerbada no contexto educacional brasileiro. Os textos apontam para os efeitos da psicopatologização de comportamentos que são comuns aos escolares. Como aponta Signor et al. (2016, p. 747), parafraseando Canguilhem, "o TDAH não é normal por ser frequente, mas é frequente por ser normal".

Para analisar de maneira consistente esse fenômeno, os autores debruçaram-se sobre as raízes históricas dessa construção científica. Não foi à toa, pois respondiam a uma demanda social. Por exemplo, em nosso país, como afirma um desses autores,

Não só a medicina, mas a psiquiatria e a psicologia tiveram um papel crucial na história desta aproximação - um tanto perigosa - entre saúde e educação. Perigosa a partir do momento em que seu objetivo era simplesmente a profilaxia dos desviantes e a consequente cura do "mau comportamento", que se expressava, sobretudo, em crianças pobres, negras e com uma estrutura familiar dissidente da norma, ou 
seja, crianças que refletiam aquilo que a psicologia e a psiquiatria foram chamadas a organizar: o caótico que é, em suma, herança do higienismo no Brasil (CRUZ; OKAMOTO; FERRAZZA, 2016, p. 705).

Neste sentido, esses últimos artigos procuram atentar para a singularidade de cada sujeito que permanece apagada diante de diagnósticos e práticas medicalocêntricas. Buscam retomar o papel central do professor, que também tem sido refém dessas práticas e acabar por concordar, pois o sistema engessa sua liberdade de atuação.

Responsabiliza, porém, os educadores, que, ao invés de investirem em metodologias criativas e inclusiva, respondem ao mal-estar do fracasso escolar com a lógica do encaminhamento, assim como os pais, que recebem da escola o feedback do mau desempenho escolar do filho e acabam rendendo-se aos efeitos "mágicos" de uma pílula.

Os artigos elencam, portanto, os pontos supracitados e que são pertinentes à discussão proposta por este trabalho. Mediante eles pudemos angariar elementos históricos para futuras discussões, pois é de extrema importância que a discussão não se esgote.

\section{CONSIDERAÇÕES FINAIS}

Nas últimas décadas, a relevância que tem se dado ao saber científico e às bases biológicas dos transtornos mentais tem nos levado a sentenciar sujeito a uma condição de vida que lhe priva de uma aprendizagem efetiva.

$\mathrm{O}$ uso indiscriminado de medicamentos com diversas finalidades tem sido um fim em si mesmo, e isso tem seu reflexo na aproximação entre saúde e educação; problemática complexa que questiona o modo de fazer ciência no âmbito da saúde, bem como a herança histórica que as ciências da saúde deixaram no contexto educacional brasileiro, psicopatologizando comportamentos dos escolares.

Ao percorrer essa trajetória de análise de artigos que vislumbram a produção científica sobre o tema nos últimos anos, vemos a presença de um discurso hegemônico em torno da criação de quadros de transtornos mentais. Percebemos a necessidade cada vez mais urgente de um olhar crítico em nossa prática, pois são esses alunos que carregam o peso da categoria diagnóstica que nos chegará enquanto aprendentes. Cabe aos profissionais psicopedagogos avaliar essa demanda como, de fato, uma demanda do sujeito aprendiz ou da instituição que o referencia.

Neste sentido, partimos da necessidade de um olhar crítico como forma de reinventar nossas práticas para que não nos engessemos em posturas que apagam os desejos do sujeito, que tem direito à aprendizagem de qualidade. Podemos, assim, contribuir para uma discussão muito mais ampla que envolve a questão da educação inclusiva em nossas escolas que, muitas vezes, se tornam práticas medicalizantes que, de fato, são excludentes. É um compromisso ético com nossos aprendentes, com o direito constitucional de aprender e formar cidadania.

Vimos, portanto, que ao longo dos últimos anos os estudos têm se voltado para essa problematização e atentado para as diferentes formas de subjetivação no contexto escolar e educacional. Também tem sido e deve continuar como uma luta incessante para que as práticas educacionais não sejam cada vez mais excludentes e que as diferentes formas de aprender sejam para todos. 


\section{REFERÊNCIAS}

ALBUQUERQUE, Guiomar; MAIA, Marcus; FRANÇA, Aniela; MATTOS, Paulo; PASTURA, Giuseppe. Processamento da linguagem no transtorno do déficit de atenção e hiperatividade (TDAH). D.E.L.T.A., 28, 2, p. 245280, 2012. Disponível em: http://www.scielo.br/scielo.php?pid=S0102-44502012000200003\&script=sci_abstract\&tlng=pt. Acesso em: 13 abr. 2019.

ALVES, Luciana Mendonça; SOUZA, Helma Tamára Vieira de; SOUZA, Vanessa Oliveira de; LODI, Débora Fraga; FERREIRA, Maria do Carmo Mangelli; SIQUEIRA, Cláudia Machado; CELESTE, Leticia Correa. Processamento fonológico em indivíduos com transtorno de déficit de atenção e hiperatividade. Revista Cefac, 16(3), p. 874-882, 2014. Disponível em: http://www.scielo.br/pdf/rcefac/v16n3/1982-0216-rcefac-16-3-0874.pdf. Acesso em: 13 abr. 2019.

AMERICAN PSYCHIATRIC ASSOCIATION. Manual diagnóstico e estatístico de transtornos mentais - DSM5. Tradução Maria Inês Corrêa Nascimento et al. Revisão técnica Aristides Volpato Cordioli et al. 5. ed. Porto Alegre: Artmed, 2014. Dados eletrônicos. Disponível em: https://edisciplinas.usp.br/pluginfile. php/4538176/mod_resource/content/1/MANUAL\%20DSM-V.pdf. Acesso em: 13 abr. 2019.

ARGOLLO, Nayara. Transtorno do déficit de atenção com hiperatividade: aspectos neuropsicológicos. Psicologia Escolar e Educacional, v. 7, n. 2, p. 197-201, 2003. Disponível em: http://www.scielo.br/pdf/pee/ v7n2/n2a10.pdf. Acesso em: 13 abr. 2019.

BELTRAME, Rudinei Luiz; SOUZA, Simone Vieira de; NASCIMENTO, Deise Maria do.; SANDRINI, Paulo Roberto. Ouvindo crianças sobre sentidos e significados atribuídos ao TDAH. Revista Quadrimestral da Associação Brasileira de Psicologia Escolar e Educacional, São Paulo, v. 19, n. 3, p. 557-565, 2015. Disponível em: http://www.scielo.br/pdf/pee/v19n3/2175-3539-pee-19-03-00557.pdf. Acesso em: 13 abr. 2019.

BENEDETTI, leda Maria Munhós; ANACHE, Alexandra Ayach. TDA/H - Análise documental sobre a produção do conceito. Revista Quadrimestral da Associação Brasileira de Psicologia Escolar e Educacional, São Paulo, v. 18, n. 3, 2014. Disponível em: http://www.scielo.br/pdf/pee/v18n3/1413-8557-pee-18-03-0439. pdf. Acesso em: 13 abr. 2019.

BRASIL. Constituição (1988). Constituição da República Federativa do Brasil, 1988. Brasília: Senado Federal; Centro Gráfico, 1988. 292 p. Disponível em: file://C:/Users/Stela/Downloads/constituicao_federal_35ed.pdf. Acesso em: 13 abr. 2019.

CALIMAN, Luciana Vieira. O TDAH: entre as funções, disfunções e otimização da atenção. Psicologia em estudo, Maringá, PR, v. 13, n. 3, p. 559-566, 2008. Disponível em: http://www.scielo.br/pdf/pe/v13n3/ v13n3a17.pdf. Acesso em: 13 abr. 2019.

CAPELLINI, Simone Aparecida; PADULA, Niura Aparecida de Moura Ribeiro; SANTOS, Lara Cristina Antunes dos.; LOURENCETI, Maria Dalva; CARRENHO, Erika Hasse; RIBEIRO, Lucilene Arilho. Desempenho em consciência fonológica, memória operacional, leitura e escrita na dislexia familial. Pró-Fono - Revista de Atualização Científica, out./dez. 19(4), p. 374-380, 2007. Disponível em: http://www.scielo.br/pdf/pfono/ v19n4/a09v19n4.pdf. Acesso em: 13 abr. 2019.

CAVADAS, Marci; PEREIRA, Liliane Desgualdo; MATTOS, Paulo. Efeito do metilfenidato no processamento auditivo em crianças e adolescentes com transtorno do déficit de atenção/hiperatividade. Arq Neuropsiquiatr., 65 (1), p. 138-14, 2007. Disponível em: http://www.scielo.br/pdf/anp/v65n1/a28v65n1.pdf. Acesso em: 13 abr. 2019.

CLASSIFICAÇÃO ESTATÍSTICA INTERNACIONAL DE DOENÇAS E PROBLEMAS RELACIONADOS À SAÚDE. CID10. Versão 1.6. 1998. Disponível em: https://www.cremesp.org.br/pdfs/cid10_ultimaversaodisponivel_2012.pdf. Acesso em: 13 abr. 2019.

COUTO, Taciana de Souza; DE MELO-JUNIOR, Mario Ribeiro; GOMES, Cláudia Roberta de Araújo. Aspectos neurobiológicos do transtorno do déficit de atenção e hiperatividade (TDAH): uma revisão. Ciência \& Cognição, v. 15, n. 1, p. 241-251, 2010. Disponível em: http://pepsic.bvsalud.org/pdf/cc/v15n1/v15n1a19. pdf. Acesso em: 13 abr. 2019.

CRUZ, Murilo Galvão Amancio; OKAMOTO, Mary Yoko; FERRAZZA, Daniele de Andrade. O caso Transtorno do Déficit de Atenção e Hiperatividade (TDAH) e a medicalização da educação: uma análise a partir do relato de pais e professores. Interface: Comunicação, Saúde e Educação, 20(58), p. 703-14, 2016. Disponível em: http://www.scielo.br/pdf/icse/v20n58/1807-5762-icse-1807-576220150575.pdf. Acesso em: 13 abr. 2019.

CUNHA, Vera Lúcia Orlandi; SILVA, Cláudia da; LOURENCETTI, Maria Dalva; PADULA, Niura Aparecida de Moura Ribeiro; CAPELLINI, Simone Aparecida. Desempenho de escolares com transtorno de déficit de atenção e hiperatividade em tarefas metalinguisticas e de leitura. Revista Cefac, 15(1), p. 40-50, jan./fev. 2013. Disponível em: http://www.scielo.br/pdf/rcefac/v15n1/67-11.pdf. Acesso em: 13 abr. 2019. 
DONZELOT, Jacques. A polícia das famílias. Trad. M. T. da Costa Albuquerque. 2. ed. Rio de Janeiro: Graal, 1986.

DORNELES, Beatriz Vargas; CORSO, Luciana Vellinho; COSTA, Adriana Corrêa; PISACCO, Nelba Maria Teixeira; SPERAFICO, Yasmini Lais Spindler; ROHDE, Luis Augusto Paim. Impacto do DSM-5 no diagnóstico de transtornos de aprendizagem em crianças e adolescentes com TDAH: um estudo de prevalência. Psicologia, Reflexão e Crítica, 27(4), p. 759-767, 2014. Disponível em: http://www.scielo.br/pdf/prc/v27n4/ 0102-7972-prc-27-04-00759.pdf. Acesso em: 13 abr. 2019.

GIL, Antônio Carlos. Como elaborar projetos de pesquisa. 4. ed. São Paulo: Atlas, 2002.

GIL, Antonio Carlos. Métodos e técnicas de pesquisa social. 6. ed. São Paulo: Atlas, 2008.

GOMES, Marcelo; PALMINI, André; BARBIRATO, Fabio; ROHDE, Luis Augusto; MATTOS, Paulo. Conhecimento sobre o transtorno do déficit de atenção/hiperatividade no Brasil. J. Bras. Psiquiatr, v. 56, n. 2, p. 94-101, 2007. Disponível em: http://www.scielo.br/pdf/jbpsiq/v56n2/a04v56n2.pdf. Acesso em: 13 abr. 2019.

INÁCIO, Francislaine Flâmia; OLIVEIRA, Katya Luciane de.; MARIANO, Maria Luzia Silva. Estilos intelectuais e estratégias de aprendizagem: percepção de professores do Ensino Fundamental. Psicologia Escolar e Educacional, São Paulo, v. 21, n. 3, p. 447-455, 2017. Disponível em: http://www.scielo.br/pdf/pee/ v21n3/2175-3539-pee-21-03-447.pdf. Acesso em: 13 abr. 2019.

JOU, Graciela Inchausti de; AMARALB, Bruna; PAVANB, Carolina Robl; SCHAEFERB, Luiziana Souto; ZIMMER, Marilene. Transtorno de déficit de atenção e hiperatividade: um olhar no Ensino Fundamental. Revista Psicologia: Reflexão e Crítica, 23(1), p. 29-36, 2010. Disponível em: http://www.scielo.br/pdf/prc/ v23n1/a05v23n1.pdf. Acesso em: 13 abr. 2019.

LDB: Lei de Diretrizes e Bases da Educação Nacional. Brasília: Senado Federal; Coordenação de Edições Técnicas, 2017.

MEIRA, Marisa Eugênia Melillo. Para uma crítica da medicalização na educação. Revista Semestral da Associação Brasileira de Psicologia Escolar e Educacional, São Paulo, v. 16, n. 1, p. 135-142, 2012. Disponível em: http://www.scielo.br/pdf/pee/v16n1/14.pdf. Acesso em: 13 abr. 2019.

OKUDA, Paola Matiko Martins; PINHEIRO, Fábio Henrique; GERMANO, Giseli Donadon; PADULA, Niura Aparecida de Moura Ribeiro; LOURENCETTI, Maria Dalva; SANTOS, Lara Cristina Antunes dos; CAPELLINI, Simone Aparecida. Função motora fina, sensorial e perceptiva de escolares com transtorno do déficit de atenção com hiperatividade. Jornal da Sociedade Brasileira de Fonoaudiologia, 23(4), p. 351-357. 2011. Disponível em: http://www.scielo.br/pdf/jsbf/v23n4/v23n4a10.pdf. Acesso em: 13 abr. 2019.

PATTO, Maria Helena Souza. A produção do fracasso escolar: histórias de submissão e rebeldia. São Paulo: Casa do Psicólogo. 2. ed. 2000. Disponível em: http://rbep.inep.gov.br/index.php/rbep/article/ view/1299/1273. Acesso em: 13 abr. 2019.

PELOSI, Miryam Bonadiu; NUNES, Leila Regina d'Oliveira de Paula. Caracterização dos professores itinerantes, suas ações na área de tecnologia assistiva e seu papel como agente de inclusão escolar. Revista Brasileira de Educação Especial, Marília, v. 15, n. 1, p. 141-154, jan./abr. 2009. Disponível em: http:// www.scielo.br/pdf/rbee/v15n1/10.pdf. Acesso em: 13 abr. 2019.

PINA, Ione Lima; MACEDO, Luciel da Silva; SEQUEIRA, Manuel Elbio Aquino; LIMA E SILVA, Iris; CARDOSO, Fabrício; PINTO, Fátima Cunha; BERESFORD, Heron. Avaliação de uma intervenção pedagógica na aprendizagem de crianças com Transtorno de Déficit de Atenção e Hiperatividade - TDAH - no âmbito das políticas públicas do Estado do Pará. Ensaio: Avaliação de Políticas Púbicas na Educação, Rio de Janeiro, v. 18, n. 66, p. 65-84, 2010. Disponível em: http://www.scielo.br/pdf/ensaio/v18n66/a05v1866.pdf. Acesso em: 13 abr. 2019.

RAGEL JUNIOR, Édison de Britto; LOOS, Helga. Escola e desenvolvimento psicossocial segundo percepções de jovens com TDAH. Paidéia, v. 21, n. 50, p. 373-382, 2011. Disponível em: http://www.scielo.br/pdf/ paideia/v21n50/10.pdf. Acesso em: 13 abr. 2019.

RODRIGUES, Carolina Innocente; SOUSA, Maria do Carmo; CARMO, João dos Santos. Transtorno de conduta/TDAH e aprendizagem da Matemática: um estudo de caso. Revista Semestral da Associação Brasileira de Psicologia Escolar e Educacional, São Paulo, v. 14, n. 2, p. 193-201, jul./dez. 2010. Disponível em: http://www.scielo.br/pdf/pee/v14n2/a02v14n2.pdf. Acesso em: 13 abr. 2019.

SENA, Soraya da Silva; SOUZA, Luciana Karine de. Percepção dos pais sobre amizade em crianças típicas e com TDAH. Psicologia Clínica, Rio de Janeiro, v. 25, n. 1, p. 53-72, 2013. Disponível em: http://www.scielo. br/pdf/pc/v25n1/04.pdf. Acesso em: 13 abr. 2019. 
SANTOS, Daniella Fernanda Moreira; TULESKI, Silvana Calvo; FRANCO, Adriana de Fátima. TDAH e boa avaliação no IDEB: uma correlação possível? Psicologia Escolar e Educacional, São Paulo, v. 20, n. 3, p. 515-522, 2016. Disponível em: http://www.scielo.br/pdf/pee/v20n3/2175-3539-pee-20-03-00515.pdf. Acesso em: 13 abr. 2019.

SIGNOR, Rita de Cássia Fernandes. Transtorno de déficit de atenção/hiperatividade: uma análise histórica e social. RBLA, Belo Horizonte, v. 13, n. 4, p. 1.145-1.166, 2013. Disponível em: http://www.scielo.br/pdf/ rbla/v13n4/aop2613.pdf. Acesso em: 13 abr. 2019.

SIGNOR, Rita de Cássia Fernandes; BERBERIAN, Ana Paula; SANTANA, Ana Paula. A medicalização da educação: implicações para a constituição do sujeito/aprendiz. Educação e Pesquisa, São Paulo, v. 43, n. 3, p. 743-763, 2017. Disponível em: http://www.scielo.br/pdf/ep/v43n3/1517-9702-ep-S1517-9702201610146773.pdf. Acesso em: 13 abr. 2019.

SIGNOR, Fernanda; LEGUISAMO, Camila Pereira; MARCHI, Ana Carolina Bertolleti de; BRAVARESCO, Suzane Stella; OLIVEIRA, Luma Zanatta de; PILATT, Ana Paula. Conhecimento e educação em saúde de idosos portadores de diabetes mellitus. Fisioterapia Brasil, v. 17, n. 2, p. 171-175. 2016. Disponível em: https://portalatlanticaeditora.com.br/index.php/fisioterapiabrasil/article/view/205/1429. Acesso em: 30 jan. 2021.

SILVA, Caroline Gonçalves Carneiro; SERRALHA, Conceição Aparecida; LARANJO, Ana Cristina Silveira. Análise da demanda e implicação dos pais no tratamento infantil. Psicologia em Estudo, Maringá, v. 18, n. 2, p. 281-291, 2013. Disponível em: http://www.scielo.br/pdf/pe/v18n2/a09v18n2.pdf. Acesso em: 13 abr. 2019.

SILVEIRA, Danielle Câmara; PASSOS, Leila Maria Avila; SANTOS, Priscila Carla dos. CHIAPPETTA, Ana Lúcia de Magalhães. Avaliação da fluência verbal em crianças com transtorno da falta de atenção com hiperatividade: um estudo comparativo. Revista Cefac, v. 11, Supl. 2, p. 208-216, 2009. Disponível em: file:///C:/ Users/Stela/Downloads/Avaliacao_da_fluencia_verbal_em_criancas_com_trans.pdf. Acesso em: 13 abr. 2019.

SIQUEIRA, Cláudia Machado; GURGEL-GIANNETTI, Juliana. Mau desempenho escolar: uma visão atual. Revista Associação Médica Brasileira, 57(1), p. 78-87, 2011. Disponível em: http://www.scielo.br/pdf/ ramb/v57n1/v57n1a21.pdf. Acesso em: 13 abr. 2019.

TOASSA, Gisele. Sociedade Tarja Preta: uma crítica à medicalização de crianças e adolescentes. Fractal, Revista de Psicologia, v. 24, n. 2, p. 429-434, 2012. Disponível em: http://periodicos.uff.br/fractal/article/ view/4905/4746. Acesso em: 13 abr. 2019.

VORCARO, A. O efeito bumerangue da classificação psicopatológica da infância. In: JERUSALINSKY, Alfredo; FENDRIK, Silvia (org.). O livro negro da psicopatologia contemporânea. São Paulo: Via Lettera, 2011. 